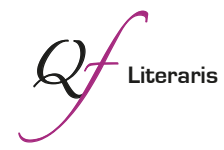

\title{
Por una epistemología de la deportación española. EI legado KL Reich de Joaquim Amat-Piniella
}

\author{
Marta Marín-Dòmine \\ Wilfrid Laurier University \\ Centre for Memory and Testimony Studies \\ mmarin@wlu.ca
}

Resumen: El abordaje crítico de KL Reich (1963), del escritor catalán Joaquim Amat-Piniella, no puede pasar por alto el hecho de que sea el libro en su calidad de símbolo más que el texto literario el que haya encontrado su lugar dentro de los iconos que representan la memoria de los españoles deportados a los campos nazis cuya memorialización está estructurada alrededor de unos lugares comunes que se han mantenido inamovibles hasta la fecha. El presente artículo ofrece una breve trayectoria de la recepción de $K L$ Reich a la luz de estos lugares comunes que configuran la articulación entre recepción y representación memorial. Terminaré por señalar una de las aportaciones literarias de KL Reich que pueden servir para ir elaborando una epistemología de la deportación española en los campos nazis.

Palabras clave: KL Reich; Joaquim Amat-Piniella; deportación; españoles en Mauthausen; literatura campos concentración.

\section{Towards an epistemology of Spanish deportation. The legacy of $K L$ Reich by Joaquin Amat-Piniella}

\begin{abstract}
The critical approach KL Reich (1963) by Catalan writer Joaquim Amat-Piniella should take into account the fact that the book as symbol rather then the literary text has has found its place among the icons that represent today's memory of the Spanish Republicans deported to Mauthausen whose memory has been constructed around very stagnated common places. This article follows briefly the reception of $K L$ Reich in light of these common places to point to the tension between reception and memorial representation. I will conclude by commenting one of the the specific contribution of KL Reich to the representation and knowledge of the Spanish deportation in Nazi camps.

Keywords: KL Reich; Joaquim Amat-Piniella; Deportation; Spaniards in Mauthausen; literature of concentration camps.



El abordaje crítico de KL Reich (1963), del escritor catalán Joaquim Amat-Piniella, no puede obviar el hecho de que hoy por hoy sea más bien el libro en su calidad de objeto y símbolo y no el texto literario el que haya encontrado su lugar dentro de los iconos que representan la memoria de los españoles republicanos deportados a los campos nazis. Esta memoria, además, se mantiene discursivamente mediante la referencia repetitiva de ciertas ideas que hasta la fecha parecen inamovibles. No es mi objetivo exponer aquí los elementos que podrían considerarse lugares comunes de la memoria de la deportación española, muchas veces creados a partir de informaciones erróneas, pero por su importancia epistemológica y la pertinencia de su análisis en este artículo quisiera detenerme brevemente en la extendida creencia que permite equiparar la deportación española al exterminio judío, y los campos de concentración a los campos de exterminio.

En el sistema nazi "Exterminio" (Vernichtung) no funcionaba como sinónimo de "asesinato" sino que era índice de un complejo plan puesto al servicio de un objetivo: llevar a cabo la "Solución final de la cuestión judía" (Endlösung der Judenfrage), que consistía en el asesinato masivo y sistemático de los judíos europeos. A este objetivo se unió más tarde el de exterminar a los sinti y roma europeos ${ }^{1}$.

A partir de 1941 el proceso de asesinato de los judíos de todas las edades en los cinco campos de exterminio o de la muerte (Vernichtungslager, Todeslager) dependientes del Reich se mantuvo más o menos regular hasta 1943: transporte desde los campos de tránsito o guetos, llegada al campo (los detenidos en su gran mayoría llegaban en familias), selección de las personas consideradas "útiles", desposesión de objetos y vestidos en el caso de ser destinadas a la exterminación, transferencia a la cámara de gas, asfixia, extracción de piezas dentales valiosas, cremación ${ }^{2}$. Este proceso, que sin duda tenía lugar en medio del gran desconcierto y pavor de las víctimas, duraba apenas unas horas.

\footnotetext{
${ }^{1}$ La persecución y exterminio de las poblaciones sinti y roma no puede tampoco ser asimilada al Holocausto. Según el historiador Georges Bensoussan (2010), los gitanos que inquietaban al Reich eran los nómadas, de tal manera que las comunidades sedentarias no fueron deportadas. Además, el Tercer Reich consideraba que ciertas comunidades gitanas pertenecían a una "raza pura" y por tanto no eran perseguidas, a pesar de que en muchos casos esta consideración se pasó por alto.

${ }^{2}$ Auschwitz-Birkenau, Chelmno, Majdanek, Sobibor, Treblinka, fueron los cinco campos de exterminio o campos de la muerte creados bajo la responsabilidad directa del Reich y destinados a la aniquilación de los judíos europeos.
} 
Mauthausen no fue diseñado para ser un campo de exterminio aunque pertenecía a una categoría de campos de trabajo extremadamente duros en los que se moría por agotamiento, inanición, palizas, enfermedad. En estos campos, la cámara de gas y el crematorio estaban al servicio de un procedimiento de muerte y eliminación de cadáveres y no como un instrumento de exterminio. Tengamos en cuenta que en 1943 en Auschwitz, por ejemplo, los crematorios II y III llegaron a quemar 5000 cuerpos diarios. Como tal, Mauthausen no estuvo tampoco destinado a los judíos, aunque los hubo y fueron objeto de especiales malos tratos como era generalizado en todos los campos del sistema nazi. El principal objetivo de Mauthausen fue la reclusión de delincuentes y otros individuos que el Tercer Reich consideraba imposibles de "reeducar", mayormente los prisioneros políticos. Mauthausen contó con una población importante de prisioneros de guerra soviéticos, polacos, checos, holandeses e italianos, además de los españoles que por razones lógicas no podían ser considerados estrictamente "prisioneros de guerra" y a los que se les designó con el triángulo azul que llevaban cosido al uniforme. A partir de 1944 fueron deportados a Mauthausen prisioneros franceses detenidos por su actividad en la Resistencia; entre ellos también hubo españoles.

A nivel de vivencia y por tanto de intento de representación de la experiencia, el exterminio de los judíos es radicalmente diferente a la deportación política, que a su vez difiere de la representación del internamiento por razones religiosas, sexuales, o puramente criminales. No se trata, por supuesto, de medir el dolor, ni de la obscenidad de implementar una escala de valores entre las víctimas. Por el contrario, la necesidad de reconocer la diferencia de experiencias surge de la voluntad de implementar una metodología que nos ayude a dilucidar las epistemologías necesariamente diversas originadas en lo que hoy se conoce de manera general como "universo concentracionario"3. En el contexto español cabría preguntarse por los beneficios de orden simbólico que

\footnotetext{
${ }^{3}$ El origen del concepto "universo concentracionario" se atribuye a David Rousset a partir de la publicación en 1946 de la obra homónima L'univers concentrationnaire. El texto de Rousset tiene como objeto testimoniar los múltiples aspectos de la experiencia vivida en un campo de concentración nazi, reflexionar sobre las consecuencias de los regímenes dictatoriales y contribuir al estudio del comportamiento humano en situaciones límite.
} 
han permitido mantener la equiparación de la experiencia de los deportados españoles con la de las víctimas del Holocausto.

En el presente artículo expondré de manera sucinta ciertos aspectos de la recepción de KL Reich a la luz de este lugar común que articula el entramado entre recepción y representación memorial. Terminaré por señalar una de las aportaciones epistemológicas de $K L$ Reich a la representación de la deportación política española en los campos nazis.

\section{De texto a objeto}

KL Reich es la representación novelada de la experiencia de un grupo de republicanos españoles en Mauthausen y sus campos satélites desde su entrada en el campo hasta la Liberación en mayo de 1945. Joaquim Amat-Piniella cuenta haber empezado a idear la obra dentro del campo $^{4}$. En 1946, el autor aprovechó su convalecencia en Andorra para dar forma a una versión cuya estructura fue la base de las versiones posteriores. A partir de 1948 y ya instalado en Barcelona, Amat-Piniella sometió el texto a múltiples reescrituras, circunstancia que vino facilitada por la dificultad que encontró para conseguir la publicación de la novela. En 1955, Amat-Piniella considera el texto finalizado, pero no consigue publicarlo hasta 1963, primero en traducción castellana ${ }^{5}$.

En el año 2001, Edicions 62 publicó una nueva versión de KL Reich bajo la responsabilidad de David Serrano. Esta fue posiblemente la circunstancia que permitió una nueva resignificación de la novela de Amat-Piniella, y probablemente un momento clave en su cristalización

\footnotetext{
${ }^{4}$ Joaquim Amat-Piniella escribió clandestinamente poemas dentro del campo que fueron recopilados y publicados en 1999 bajo el título Les llunyanies.

${ }^{5}$ Seix Barral publicó la traducción castellana firmada por Baltasar Porcel, con el entrecomillado a manera de subtítulo "Miles de españoles en los campos de Hitler". El título de la edición catalana de 1997 reza KL Reich. Els catalans als camps d'extermini de Hitler. En 2002 Muchnick publica la traducción al castellano de Antonio Padilla que parte de la versión catalana publicada por Edicions 62. Finalmente, en 2014 Libros del Asteroide publica una nueva edición que retoma la aparecida originalmente en Seix Barral, esta vez con prólogo de Ignacio Martínez Pisón. De KL Reich existe la versión inglesa publicada en 2014 por Wilfrid Laurier University Press de Canadá con introducción crítica de Marta Marín-Dòmine, y cotraducción de Robert Finley y Marta Marín-Dòmine. Mientras escribo me acaba de llegar noticia de la publicación de la traducción alemana hecha por Kirsten Brandt para Czernin Verlag, con epílogo de Marta Marín-Dòmine.
} 
como unos de los símbolos de la memoria de los españoles en los campos nazis. De esta versión llama la atención el aparataje paratextual que apoya la afirmación de ser la "versión completa y sin censurar" de la obra que Amat-Piniella había escrito en 1946, con lo cual se invalidan -se supone que por incompletas- las versiones de Club Editor y Seix Barral, responsables respectivamente de las ediciones catalana y castellana ${ }^{6}$. A partir de esta supuesta recuperación se ha ido tejiendo un discurso en el que interviene uno de los topos de la configuración memorial: una maleta en cuyo interior Serrano afirma haber hallado cuatro fragmentos excluidos de las ediciones de $1963^{7}$. De esta manera, la versión de 2001 se erige como restitución simbólica de lo silenciado por la memoria oficial y por tanto KL Reich es resignificada en calidad de objeto recuperado más que como texto literario.

No cabe duda de que esta reactualización de KL Reich no se debió exclusivamente a la reedición del 2001, más bien se podría decir que la nueva versión apareció en un momento de confluencia -y quizás incluso como producto mismo de este momento- en el cual la sociedad española reclamaba de manera contundente un lugar para la memoria de los vencidos de la guerra civil y de la dictadura. Por esta razón no es de sorprender que la nueva edición de KL Reich fuera recibida de manera acrítica no tan sólo por la prensa escrita, sino incluso después de pasado un cierto tiempo por parte de publicaciones especializadas, pues viene a dar respuesta al ambiente reinante que hasta la fecha reclama justicia memorial. KL Reich ha pasado a ser un documento más que un relato, una prueba del avance en la restitución del pasado más que una representación literaria de éste ${ }^{8}$.

De manera más bien sintomática, la celebración en 2014 del centenario del nacimiento de Joaquim Amat-Piniella no produjo tampoco análisis críticos de $K L$ Reich que pudieran abrir nuevas perspectivas de lectura. Un año después, la conmemoración internacional del 70 aniversario de la liberación de los campos nazis tampoco sirvió para que en España aparecieran nuevos aportes para entender la formación y mantenimiento de los lugares comunes utilizados para describir la memoria de la deportación española, por otra parte tan cómodos a la

\footnotetext{
${ }^{6}$ Véase a guisa de ejemplo, la reseña de Isabel Obiols (2001).

${ }^{7}$ Así lo narra el mismo David Serrano en su blog: https://dserranoblanquer.wordpress. com/amat-piniella/ Último acceso, 30 de setiembre de 2016.

${ }^{8}$ Véase como ejemplo: Maria Campillo (2003).
} 
prensa escrita, y continuamente alimentados por documentales producidos por cadenas oficiales que sin ningún tipo de escrúpulos facilitan la asimilación de acontecimientos históricos produciendo, como efecto paradójico, la invisibilidad de todos ellos?.

Pero volvamos al caso concreto de KL Reich y a la versión de 2001. No perdamos de vista que la difusión de la obra antes de 2014 llegó a su máximo apogeo entre los años 2005 y 2007 al ser recomendada lectura de interés en los institutos de enseñanza media catalanes. En un país como España, en el que por razones varias la historia del nazismo y de sus víctimas ha experimentado numerosos silencios y desintereses y en el que, por tanto, la historia y la memoria de los campos nazis no forman parte del tejido memorial colectivo ${ }^{10}$, el cambio de siglo y sus conmemoraciones reforzó la asimilación memorial, de manera que la deportación política española quedó fijada a los significantes que representan la memoria del Holocausto. Recordemos que en el 2005 España se sumó por primera vez a los actos oficiales que a nivel internacional conmemoraron la memoria de Auschwitz. No obstante, en el acto celebrado en el Congreso de los Diputados no faltó la representación de los españoles deportados a los campos nazis, a pesar de existir un día específico para conmemorar la memoria de los distintos campos de concentración, que normalmente corresponde a la fecha de su liberación.

La asimilación de memorias, la equiparación de los campos de exterminio con los campos de concentración, la indiferenciación de ex-

${ }^{9}$ Entre 2014 y 2015 aparecieron unas pocas obras relacionadas con la memoria de Mauthausen y con la deportación española. La más controvertida fue sin lugar a dudas El impostor (2014) de Javier Cercas centrada en la biografía de Enric Marco, un falso testimonio. En 2015 aparecieron la reedición de la biografía del fotógrafo Francesc Boix publicada previamente en el 2002 (Benito Bermejo, 2015) ahora con prólogo de Javier Cercas, y la recopilación de testimonios a cargo de Carlos Hernández de Miguel. Finalmente, Libros del Asteroide publicó ese mismo año la reedición de la traducción española de KL Reich publicada inicialmente por Seix Barral, con un prólogo de Ignacio Martínez de Pisón que abunda en los lugares comunes utilizados para comentar la novela (2015: x). Por lo que se refiere a las publicaciones especializadas sobresale el trabajo de Vicent Simbor (2014: 217-246). Por lo que se refiere a documentales, véase como ejemplo Montserrat Armengou y Ricard Belis (2004).

${ }^{10}$ Vale la pena mencionar el rechazo que por parte de la Generalitat de Catalunya obtuvo la propuesta del diputado Josep Benet de erigir un monumento en homenaje a los catalanes muertos en los campos nazis (Boletín Oficial del Parlament de 27 de febrero de 1981). Recordemos que fue Josep Benet quien propuso a Montserrat Roig el proyecto de investigar la deportación catalana. 
periencias y por tanto la falta de una perspectiva histórica que permita entender la importancia de establecer una metodología que tenga presente estas diferencias, en definitiva el sostenimiento de lugares comunes en el abordaje de la historia y la memoria de los campos nazis, se podría entender como una manera subliminal de asegurar la inclusión a pleno derecho de España en el tejido memorial europeo. El prólogo de David Serrano (2001: 8 y 13) a la edición de Edicions 62 deja clara la perspectiva aglutinadora al afirmar de manera totalmente acrítica que $K L$ Reich forma parte del corpus concentracionario europeo totalmente indiferenciado.

Así, en el 2001 se produce un giro en la recepción de KL Reich que delinea un arco cuya trayectoria de recepción se inició en los años 60 con su inclusión dentro de la novela realista de posguerra, tal y como la había fijado Joaquim Molas (1966: 19-21), continúa con la consideración de ser la novela épica de la representación de los españoles y catalanes en los campos nazis, según lectura que hacen de ella Montserrat Roig (1977: 12) y Joan Triadú (1982: 151), hasta ser considerada su inclusión dentro del canon concentracionario europeo por parte de David Serrano (2001: 8 y 13). Lo más llamativo de la recepción anterior al siglo veintiuno es la falta de instrumentos metodológicos para entender la especificidad de la literatura que surge de los campos de concentración, falta que indica también la impermeabilidad de los especialistas del país respecto a los trabajos que se han ido produciendo más allá de las fronteras españolas.

Joaquim Amat-Piniella, ya se ha dicho, compuso un primer borrador de KL Reich en Andorra. Aunque fuera de España, al autor no se le podían haber pasado por alto las dificultades que encontraría la publicación de la novela en territorio español. A pesar de todo, no me parece suficiente atribuir estas dificultades tan sólo a la censura. Sabemos, por ejemplo, que en 1953 Agustí Bartra mostró interés en publicar KL Reich en México. Sabemos también que Amat-Piniella por esas fechas no consideraba que hubiera alcanzado la versión definitiva de KL Reich; de hecho, no será hasta 1955 cuando afirme tener la sensación de haber logrado la versión final ${ }^{11}$. Durante este trabajo de reelaboración AmatPiniella habrá descartado y archivado en una carpeta cuatro fragmentos largos, algunos de los cuales aparecen reescritos sintéticamente en

\footnotetext{
${ }^{11}$ Arxiu del Bages.
} 
la versión final. Es precisamente esta versión reelaborada la que pasa finalmente la censura una vez que Carlos Barral la presenta en 1961 para su publicación en castellano dentro de la colección "Testimonio" 12 . Amat-Piniella comentó después a Joan Sales, su editor catalán, que la censura no había "tocado ni una sola coma" de la versión presentada por Barral ${ }^{13}$. Unos meses después, Sales publica la obra en su versión original catalana, en Club Editor. Como curiosidad cabe señalar que el mismo Carlos Barral no consigue la aprobación de la censura para publicar la traducción castellana de Le grand voyage de Jorge Semprún ${ }^{14}$. Los vericuetos de la censura de la época son sin duda complejos, y más en los años 60, período durante el cual el Gobierno español pretendió relajar el control sobre la producción cultural como estrategia de obertura y acercamiento a Europa.

A pesar de todo, la exclusión de los fragmentos mencionados de la versión definitiva de KL Reich no parece haber sido fruto de la censura, o al menos no hay constancia de ello en la documentación consultable en el Archivo General de la Administración. En este caso cabría considerarse como fruto de una decisión personal cuyas razones ignoramos, pero que dada la reelaboración e incorporación de algunos de los fragmentos a la versión definitiva, podemos atribuir a razones estéticas o más probablemente a razones de contenido, ya que dos de estos fragmentos se refieren al trato bárbaro del que fueron objeto los judíos y los deportados yugoslavos. Para sostener esta hipótesis nos irá bien tener en cuenta ciertos aspectos del contexto político francés lugar de exilio de muchos de los supervivientes españoles. Estas indicaciones son un primer paso para entender la confluencia de posturas entre la militancia clandestina de ambos países ${ }^{15}$.

En junio de 1945 Nuestra Bandera, revista del PCE editada en Toulouse, publicaba el informe leído en aquella ciudad por Santiago Carrillo el 14 de mayo de 1945 (es decir, nueve días después de la liberación del campo de Mauthausen) con la finalidad de dar cuenta de la situación del Partico Comunista Español tras la capitulación de Alemania y alertar a la militancia de los posibles "infiltrados". Estos, comenta Carrillo,

\footnotetext{
${ }^{12}$ La versión que Carlos Barral presentó a censura en 1961 fue la versión previamente presentada en 1955.

${ }^{13}$ Arxiu del Bages.

${ }^{14}$ Jorge Semprún (1996: 350-351).

${ }^{15}$ Sobre este aspecto véase Jorge Semprún (1977).
} 
pueden encontrarse entre los grupos de supervivientes españoles de los campos nazis, por lo que avisa: "Sin desconfiar de nuestros camaradas, debemos conocer qué es lo que han hecho, cómo se han comportado, vigilar aquellos cuya situación sea algo dudosa [...]" (Carrillo, 1945: 19).

Intuyendo las exigencias que el Partido haría recaer sobre los supervivientes, los militantes y simpatizantes comunistas españoles celebran, una semana después de la liberación de Mauthausen, una asamblea dentro del campo que parece funcionar como ejercicio de autocrítica. Mariano Constante en Los años rojos lo comenta de esta manera: "Nuestra organización política preparó una asamblea extraordinaria para dar cuenta de cuáles habían sido nuestras actividades durante cerca de cinco años de encierro en Mauthausen" (Constante, 1979: 192).

Por lo que se refiere a la situación en Francia, hay que señalar que el Partido Comunista Español se pudo reorganizar en el exilio gracias al apoyo del partido francés que en este momento gozaba de una influencia notable en el ámbito editorial. Es así como las narrativas testimoniales que aparecen publicadas en Francia a partir de 1946 tienen como denominador común dar cuenta de los valores de la militancia comunista. No será hasta bien entrada la década de los 60 cuando se reconocerán de manera general, y no tan sólo esporádica, las narrativas testimoniales pertenecientes al Holocausto propiamente dicho ${ }^{16}$.

Por supuesto el tema es de una complejidad de la cual el presente artículo no puede dar cuenta. De todas maneras, es bueno tener presente estos datos generales para poder entrever las dificultades que pudieron tener algunos textos testimoniales cuyo contenido no tenía como objetivo primero ensalzar la deportación comunista. Recordemos, además, que miembros destacados de la Amicale de Mauthausen en París, tales como Emily Valley, Paul le Caër y Pierre Daix, habían formado parte del Comité Internacional del campo con representación masiva de comunistas ${ }^{17}$. Así mismo, la Amical de Mauthausen y otros campos, que se fundó en Barcelona, contaba entre sus integrantes con una propor-

\footnotetext{
${ }^{16}$ Régine Waintrater (2003: 42) afirma que los primeros testimonios publicados pertenecían mayoritariamente a autores miembros de partidos políticos y no a judíos sin afiliación política.

${ }^{17}$ Es conocido el recelo e incluso el trato injusto de que fueron objeto los supervivientes por parte de los partidos comunistas europeos. Stalin consideró que detrás de cada superviviente se escondía un colaborador. Para un análisis detallado de este aspecto véase Pierre Daix (2005: 58-59) y Rosa Toran (2007: 204-205).
} 
ción significativa de exmilitantes y simpatizantes de las diversas formaciones comunistas que habían existido en la España republicana.

De la cantidad de escritos que empiezan a circular a partir de 1946 en Francia sobresalen L'univers concentrationnaire (1946) de David Rousset y L'Espèce Humaine (1947) de Robert Antelme. Notemos además que sus autores estaban afiliados por aquel entonces al Partido Comunista Francés. En contraposición, y como ejemplo manifiesto de la dificultad de publicación que hallaban los textos escritos por autores no encuadrados en el partido, quiero citar el libro testimonial escrito por François Wetterwald, médico exdeportado a Mauthausen y trasladado a Ebensee en calidad de cirujano. En el prólogo que Wetterwald escribe para la reedición de 1991 de su libro testimonial Les morts inutiles, atribuye la retirada forzada de la edición de 1945 a la intervención directa de Louis Aragon, antiguo resistente, ferviente militante del Partido Comunista Francés y por aquel entonces influyente editor responsable de Les Éditions de Minuit.

Recordemos para concluir sobre este punto, la reacción altamente adversa y virulenta al llamado de David Rousset, en 1949, dirigido a intelectuales y escritores franceses para que exigieran una investigación sobre los campos de concentración soviéticos. Valga decir que en 1950 tanto David Rousset como Robert Antelme ya no pertenecen al Partido Comunista Francés.

En el caso concreto de KL Reich no hay duda de que Amat-Piniella era plenamente consciente de las dificultades que suponía la publicación de una novela que presentaba no sólo los conflictos entre deportados españoles en Mauthausen, heredados de los conflictos partidistas e ideológicos entre comunistas y anarquistas, sino que además contaba con otros elementos textuales comprometidos como el de rescatar ni que fuera por la vía novelada, a César Orquín a través del personaje de August $^{18}$. Si bien hasta la fecha no me ha sido posible dar con material documental que pueda aportar información concreta sobre la recepción de K.L. Reich entre los exdeportados catalanes y españoles, quiero mantener mi hipótesis de que el contenido de la novela pudo haber causado

\footnotetext{
${ }^{18}$ David Pike (2008: 100-101) confirma la mala prensa de la que fue objeto César Orquín entre los comunistas. Por su parte, los comunistas Constante y Razola (1979: 9697) lo señalan como responsable de numerosos abusos. El superviviente francés Paul Le Caër (1996: 90) también menciona la mala relación de Orquín con ciertos grupos de españoles.
} 
cierto desconcierto entre el círculo de supervivientes. Por lo que se refiere al caso concreto de la recuperación de Orquín, sólo cabe comentar la existencia de una carta escrita en 1991 por el exdeportado anarquista Francesc Comellas, dirigida a Odette Ester, esposa del exdeportado anarquista José Ester Borrás. En la carta, Comellas critica de manera contundente el libro Triángulo Azul de Mariano Constante y Razola, afiliados al PCE, por tratar de "bandido y provocador" a César Orquín.

Estas pinceladas, aunque generales, pueden hacer intuir un ambiente dentro de los círculos de exdeportados poco propicio a la publicación de obras testimoniales que no ensalzaran a los camaradas comunistas. $K L$ Reich no fue, ciertamente, el tipo de narración esperada por algunos.

\section{El legado del texto: un saber deportado ${ }^{19}$}

Es indiscutible que el alto nivel de referencialidad de KL Reich contribuyó a que fuera considerada como documento tal y como lo atestiguan, entre otros, el trabajo de Montserrat Roig (1977), que llega a tomar prestados ciertos pasajes de la novela para validar la información histórica, y también el estudio de Joan Triadú (1982: 133). Amat-Piniella consideró KL Reich una novela testimonio, que combinaba elaboración literaria y voluntad documental ${ }^{20}$. A pesar de todo, escasos son los estudios que han señalado las particularidades literarias de KL Reich y los aportes que ofrece al corpus textual de la deportación española y europea, un corpus que dicho sea de paso todavía está por hacer. La mayoría de los análisis se ciñen a la descripción narrativa, y casi siempre suelen confundir la narración con el acontecimiento histórico, de manera que la novela es considerada reflejo fiel de lo acontecido. Además, se han valorado en ella otros elementos que forman parte del tejido paratextual que acompaña la comercialización de la novela, como es su fecha temprana de escritura ${ }^{21}$.

\footnotetext{
${ }^{19}$ Tomo la expresión "saber deportado" de Anne-Lise Stern (2007).

20 " [KL Reich] Es una novela testimonial en la que pretendo contar la vida y la muerte de miles de españoles que pasaron por aquel campo. No es la historia de un campo. Pretendo simbolizar todos los lugares donde se concentraba a los prisioneros. Es la experiencia de mi estancia en cinco campos." (1966), en http://www.memoria.cat/amat/content/ lopinió-damat-piniella-sobre-la-seva-novel·la-klreich/ Último acceso, 30 de setiembre de 2016. La traducción es mía.
}

${ }^{21}$ Véase Marta Marín-Dòmine (2013: 348). 
Otro de los aspectos de KL Reich potencialmente controvertido es el de ser un texto novelado. Esta controversia se ha tendido a minimizar valorando la elección del autor sin atender a una perspectiva crítica que ponga al descubierto las tensiones implícitas en esta elección ${ }^{22}$.

Amat-Piniella justificó el recurso a la ficción afirmando en el prólogo que esta elección le había permitido llegar a la "verdad íntima" de los que pasaron por la experiencia. Esta afirmación es extremadamente relevante porque a pesar de la vaguedad que subyace en el concepto empleado por el autor, hay algo en él que remite a la noción de indecibilidad que es clave en el debate sobre la representación literaria de los campos nazis. Si esto es así, Amat-Piniella estaría afirmando que desde su subjetividad la vía posible para salir de lo imposible de la representación es la ficción, postura problemática cuando es referida a la literatura testimonial que exige, por convención, una fuerte aproximación entre el "yo" narrativo y el autor.

El uso de la ficción para representar la experiencia produjo en Francia un fuerte debate ya en 1946, coincidiendo con la publicación de los primeros testimonios. El debate retomaba de alguna manera otro, de cariz similar, iniciado por Jean-Norton Cru (1929) a propósito de la representación y veracidad de los relatos sobre la experiencia de los soldados en la Primera Guerra Mundial ${ }^{23}$. Y es que recurrir a la ficción suele tener unos objetivos que sobrepasan a los manifestados por el mismo autor -como el de procurar un efecto de distanciamiento entre su persona y lo narrado- que, en el caso que nos ocupa y atendiendo a las posibles dificultades de recepción que se han ido mencionando, pueden ser harto significativos.

La ficción permite además llenar el vacío de significación que conlleva una experiencia límite. Elementos narrativos son también la ideología, las acciones clandestinas, los actos de solidaridad que por aña-

\footnotetext{
22 David Serrano se ocupó de este aspecto en su tesis doctoral "La literatura concentracionària europea: Joaquim Amat-Piniella" (2003: 16-73). Aquí me limito a destacar un aspecto más del extenso debate sobre el uso de la ficción en los textos escritos por supervivientes de los campos nazis. Este debate sigue suscitando reflexiones y cuenta hoy en día con una amplia bibliografía. Para una síntesis de este debate véase Barbara Pirlot (2007).

${ }^{23}$ Jean Cayrol, escritor superviviente de Gusen y guionista del film Nuit et Brouillard de Alain Resnais, fue crítico acérrimo del uso de la ficción para representar los campos nazis. Para más detalles, véase Marta Marín-Dòmine (2013: 354-360) y Marta MarínDòmine (2014b: xvi-xix).
} 
dido facilitan las posibilidades de supervivencia y además organizan narrativamente lo vivido. Así, para el deportado español -y por extensión para todo deportado político-, y a diferencia del deportado judío que es víctima por "ser" y no por "actuar", la ideología y las acciones que conlleva otorgan propósito a la experiencia tal y como queda tematizado en el final de KL Reich, cuya conclusión es la esperanza del triunfo del "Hombre" por encima del nazismo. Es interesante notar a este respecto que el objetivo principal buscado por las organizaciones políticas clandestinas en los campos de concentración fue por encima de todo el de mantener la moral entre los deportados y la pertinencia de los principios ideológicos que habían animado la anterior actividad política. Es decir, la ideología permitía construir una narración a través de la cual sostenerse individual y colectivamente. Es pues comprensible que en KL Reich la organización clandestina sea uno de los focos centrales de la narración, especialmente en sus últimos capítulos.

Literatura, ficcionalización puesta al servicio de la representación de una experiencia polifónica en la que cada voz permite ir configurando el acontecimiento de principio a fin. Estamos necesariamente lejos de la escritura primera de Primo Levi (1947) que rehúye la creación de universos textuales conclusos sujetos a un desarrollo cronológico. AmatPiniella, por el contrario, no arriesga experimentos literarios a los que se diría que fue inclinado en su juventud si nos atenemos a su implicación en la creación de la revista manresana Ara (1930-32), interesada por la vanguardia literaria. En KL Reich, en cambio, el autor utiliza los recursos de la novela realista, incluyendo el uso del lenguaje cinematográfico (panorámicas, planos de detalle que escrutan los objetos o las reacciones de los personajes, acciones paralelas), puestos al servicio de un narrador omnisciente que se sitúa a una distancia de lo narrado, con lo cual el autor logra un efecto de objetividad que ha conseguido convencer incluso a algunos de los críticos (Triadú: 151).

$K L$ Reich parece tener como función organizar retrospectivamente la experiencia, narrarla con la lógica del relato tradicional, mostrar la anormalidad a través del universo reglado del lector. ¿Qué otra cosa podría justificar, por ejemplo, el abuso de reflexiones intelectuales de Emili, el personaje principal, dentro del campo, si no es por efecto de esta "memoria retrospectiva" necesaria en la elaboración de toda narrativa testimonial y también instrumento puesto al servicio de la tarea de humanizar la experiencia allí donde el verdugo tenía proyectado conseguir lo contrario? 
Primo Levi señala al deportado político como cronista privilegiado de los campos nazis ya que le estaba dado interpretar los hechos recurriendo a su bagaje ideológico (1989: 17). Amat-Piniella se encuentra, efectivamente, entre estos casos a los cuales Levi otorga la calidad de cronistas, actividad que el autor catalán vehicula textualmente a través de la mirada, siendo esta función una de las aportaciones de KL Reich a una epistemología de la experiencia ${ }^{24}$. Esta mirada, que surge con voluntad documental y que convierte al sujeto que mira en testimonio narrativo, se construye en contraposición a la mirada del verdugo, es decir la mirada del sujeto que goza del sufrimiento del otro y a cuyo cuestionamiento es invitado de manera implícita el lector. Veamos en lo que sigue una síntesis de esta articulación.

Francesc, el personaje que encarna la lealtad personal y política, muere como consecuencia de una serie de acontecimientos producidos por su negativa a cumplir con la orden de un SS, actitud por la que será físicamente castigado. Francesc termina asesinado por inyección de gasolina, sistema de eliminación utilizado en Mauthausen para deshacerse de los enfermos irrecuperables. La caída inexorable de Francesc en el universo de los "incurables" tiene su génesis en la curiosidad de mirar. Ante la escena de un SS golpeando a un judío, Francesc no puede resistir la extraña fascinación de la sangre. Es precisamente este goce que Amat-Piniella tiene la valentía de tematizar, el elemento que constituye un eslabón en el análisis epistemológico en la representación de la deportación política en los campos nazis. Como añadido no quiero dejar de señalar la estrategia narrativa de introducir en esta escena de articulación de miradas a un personaje judío índice de la víctima paradigmática de los campos nazis ${ }^{25}$.

Francesc se redime de su goce negándose a compartir el goce del torturador, negativa que paga con su propia muerte. El testimonio interpuesto de este acontecimiento pasa a ser Emili, su amigo, quien a partir de la muerte de Francesc decide observar para testimoniar. En la mirada de Emili se encuentra, así, la génesis del testimonio. Notemos a propósito que el nombre de Emili remite al Emilio de J. J. Rousseau,

\footnotetext{
${ }^{24}$ Para un análisis más detallado sobre la función de la mirada en véase Marta MarínDòmine (2013: 360- 364) y Marta Marín-Dòmine (2014b: 153-166).

${ }^{25}$ Jorge Semprún (1996: 150) comenta que la creación de un personaje que encarna a un deportado judío se le impuso como manera de subrayar a través de él a la víctima por excelencia de los campos nazis.
} 
ideal del hombre nuevo que surge del pacto social y que por tanto hace posible el mantenimiento de la comunidad humana. Amat-Piniella confiere a Emili el privilegio de acceso a ciertas zonas del campo vedadas a la mayoría, como es el crematorio, manera de plasmar la "verdad íntima" de la experiencia con el objetivo de hacer visible lo que queda fuera del campo de visión. De manera simbólica, pues, Emili se otorga la responsabilidad de transmitir lo observado y, con ello, darle sentido, es decir "humanizarlo".

$K L$ Reich no es la novela del Holocausto español, pura y simplemente porque no lo hubo. No es tampoco "la" novela de la deportación española pura y simplemente porque ninguna obra puede dar cuenta de la totalidad de un acontecimiento histórico, sino de retazos arrancados a la experiencia subjetiva. KL Reich es una pieza importante, sin lugar a dudas, en la representación de esta memoria, y una contribución inestimable si queremos abordar la diversidad epistemológica que subyace en la experiencia de la deportación política. Una memoria que, tal y como plasma la novela, es múltiple, necesariamente matizada. Memoria que también es vestigio del Mal, tal y como queda textualmente reflejado en el título ("KL Reich" es la marca que llevan en la ficción los objetos del campo).

Del texto de Amat-Piniella se desprende, además, una lección que viene a apoyar la necesidad de tener en cuenta las historias subjetivas frente a la historia oficial: no hay destino heroico, sino contingencia. Circunstancia que no excluye el compromiso ético individual puesto que dentro de la contingencia el ser humano elige. Teniendo en cuenta este aspecto quizás podamos acomodar en nuestra lectura el final altamente moralizante que nos ofrece KL Reich. Pero KL Reich es también, en la línea general adoptada por la literatura testimonial, un intento de ofrecer a los muertos un lugar de memoria ${ }^{26}$.

\section{Bibliografía}

Amat-Piniella, Joaquim. 1963a. KL Reich. Barcelona: Seix Barral. Castellano. Traducción de Baltasar Porcel y del autor.

Amat-Piniella, Joaquim. 1963b. KL Reich. Barcelona: El Club Editor. Catalán.

\footnotetext{
${ }^{26}$ La versión de KL Reich de 1946 llevaba el significativo subtítulo de Morts sense sudari (Muertos sin mortaja). Archivo General de la Administración.
} 
Amat-Piniella, Joaquim. 1999. Les llunyanies. Poemes de l'exili (1940-1946). Barcelona: Columna.

Amat-Piniella, Joaquim. 2001. KL Reich. Barcelona: Edicions 62. Catalán. Prólogo de David Serrano.

Amat-Piniella, Joaquim. 2002. KL Reich. Barcelona: El Aleph. Castellano. Traducción de Antonio Padilla.

Amat-Piniella, Joaquim. 2013. KL Reich. Epílogo de Marta Marín-Dòmine. Barcelona: Club Editor. Catalán.

Amat-Piniella, Joaquim. 2014. KL Reich. Barcelona: Libros del Asteroide. Traducción de Baltasar Porcel y del autor. Prólogo de Ignacio Martínez de Pisón.

Antelme, Robert. [1947] 2001. L'espèce humaine. París: Gallimard.

Armengou, M. \& Belis, Ricard. 2004. El convoy de los 927 [50 min]. Televisió de Catalunya.

Bensoussan, Georges. 2010. ¿Auschwitz por herencia? Sobre un buen uso de la memoria. Barcelona: Anthropos.

Bermejo, Benito. 2002. Francisco Boix: el fotógrafo de Mauthausen. Barcelona: RBA.

Bermejo, Benito. 2015. El fotógrafo del horror. La historia de Francisco Boix y las fotos robadas a los SS de Mauthausen. Barcelona: RBA.

Campillo, Maria. 2003. Memòria literària i ficció de l'univers concentracionari. En Sobrequés, Jaume; Molinero, Carme \& Sala, Margarida (eds.) Els camps de concentració $i$ el món penitenciari a Espanya durant la guerra civil i el franquisme. Barcelona: Museu d'Història de Catalunya/Crítica, 119-131.

Carrillo, Santiago. [1945] 1977. La situación de España y nuestras tareas después de la victoria de las Naciones Unidas. Nuestra Bandera. Revista mensual de orientación política, económica y cultural. Partido Comunista de España (Edición Facsímil). Madrid, número 2: 7-20.

Cercas, Javier. 2014. El impostor. Barcelona: Random House.

Comellas, Francesc. Correspondencia. En José Ester Borrás 10622/ ARCH02428. International Institute of Social History, Amsterdam.

Constante, Mariano \& Razola, Manuel. 1979. Triángulo azul: los republicanos españoles en Mauthausen, 1940-1945. Barcelona: Edicions 62.

Cru, Jean-Norton. [1929] 2006. Témoins. Nancy: Presses universitaires de Nancy. Introducción y epílogo de Frédéric Rousseau.

Daix, Pierre. 2005. Bréviaire pour Mauthausen. París: Gallimard, 58-59.

Hernández de Miguel, Carlos. 2015. Los últimos españoles de Mauthausen. Barcelona: Ediciones B.

Le Caër, Etienne \& Paul. 1996. K.L. Mauthausen. Les cicatrices de la mémoire. Bayeux: Éditions Heimdal, 90. 
Levi, Primo. [1947] 1987. Si esto es un hombre. Barcelona: Muchnick Editores.

Levi, Primo. [1986] 1989. Los hundidos y los salvados. Barcelona: Muchnick Editores.

Marín-Dòmine, Marta. 2013. Epílogo a KL Reich. Barcelona: Club Editor: 327-364.

Marín-Dòmine, Marta. 2014a. Visión y mirada en un texto sobre la deportación en Mauthausen: KL Reich de Joaquim Amat-Piniella. En Lakhdari, Sadi \& Enache, Irina (eds.) Voir, se voir, être vu. La pulsion scopique dans la littérature hispanique contemporaine. París: Éditions l'Harmattan, 153-166.

Marín-Dòmine, Marta. 2014b. Introducción a KL Reich. Waterloo: Wilfrid Laurier Press, vii-xxii.

Martínez de Pisón, Ignacio. 2014. Prólogo a KL Reich. Barcelona: Los Libros del Asteroide, VII-X.

Molas, Joaquim. 1966. La literatura de postguerra. Barcelona: Rafael Dalmau, 19-21.

Obiols, Isabel. 2001 (30 de julio). Edicions 62 publica la versión original de "K. L. Reich", descubierta en 1997. El País, en http://elpais.com/diario/2001/07/30/catalunya/996455251 850215.html

Pike, David. 2008. Españoles en el Holocausto. Barcelona: Debolsillo, 100101.

Pirlot, Barbara. 2007. Après la catastrophe: mémoire, transmission et vérité dans les témoignages de rescapés des camps de concentration et d'extermination Nazis. Civilisations 56: 21-41. URL: http://civilisations.revues.org/86; DOI: 10.4000/civilisations.86. [Acceso: 15/10/2016].

Roig, Montserrat. 1977. Els catalans als camps nazis. Barcelona: Edicions 62.

Rousset, David. 1946. L’Univers concentrationnaire. París: Éditions du Pavois.

Semprún, Jorge. 1977. Autobiografía de Federico Sánchez. Barcelona: Planeta.

Semprún, Jorge. 1996. L'Écriture ou la vie. París: Gallimard.

Serrano, David. 2001. Prólogo a KL Reich. Barcelona: Edicions 62, 7-13.

Serrano, David. 2003. La literatura concentracionària europea: Joaquim Amat-Piniella (Tesis Doctoral). Bellaterra, Universitat Atònoma de Barcelona, Departamento de Filología Catalana. http://www.tesisenred.net/ bitstream/handle/10803/4843/dsb1de2.pdf?sequence=1\&isAllowed=y [Acceso 15/10/2016].

Serrano, David. Blog del autor: https://dserranoblanquer.wordpress.com/amatpiniella/ 
Simbor, Vicent. 2014. Les novel·les dels camps de concentració. Caplletra: Revista Internacional de Filologia 36: 217-246. doi: 10.7203/caplletra.36.4902

Stern, Anne-Lise. 2007. Le Savoir-déporté: Camps, Histoire, Psychanalyse. París: Points.

Toran, Rosa. 2007. Joan de Diego. Tercer secretari a Mauthausen. Barcelona: Edicions 62, 204-205.

Triadú, Joan. 1982. La novel·la catalana de postguerra. Barcelona: Edicions 62.

Waintrater, Régine. 2003. Sortir du genocide. Témoigner pour réapprendre à vivre. París: Payot, 42.

Wetterwald, François. [1945] 2009. Les morts inutiles. París: L'Harmattan.

\section{Otras fuentes}

Archivo Joaquim Amat-Piniella en Arxiu del Bages.

Boletín Oficial del Parlament (BOP) de 27 de febrero de 1981.

International Institute of Social History, Amsterdam. 
